\title{
Transparency from Space: North Korea through the Eyes of the United States
}

\author{
PHILIPP OLBRICH* \\ Department of International Relations and International Organization, Uni- \\ versity of Groningen, the Netherlands
}

\section{Introduction}

The commercialization of satellite imagery has culminated into expectations of global transparency. For the past 20 years, companies have launched private, high-resolution remote sensing satellites to create an expansive low-orbit infrastructure. Contrary to the Cold War, this enables non-governmental users to monitor and publicize human security hotspots on a worldwide scale. Since the commercialization of satellite imagery, the Democratic People's Republic of Korea (DPRK or North Korea) has become a central focus of universities, think tanks and non-governmental organizations (NGO) to shed light on the allegedly hermit kingdom. ${ }^{1}$ The heatmap serves to critically examine the claims of uniform transparency using the example of North Korea. For this purpose, it visualizes the geospatial distribution of high-resolution satellite imagery taken by the U.S.-based industry leader DigitalGlobe over North Korean territory from 2002 through 2017. The data was derived from the company's ImageFinder tool that lets users specify an area of interest, time period and other options to show all available imagery that fulfills predefined criteria. ${ }^{2}$ The information for each image was copied and manually entered into a Microsoft Excel 2013 sheet. Then, a dynamic heatmap was produced by the Power Map add-in that plots the data on a basemap over time. The heatmap displayed here shows all accumulated data points until December 31, 2017. One data point on the map represents the center of one high-resolution satellite image. These images can either be a long strip, a rectangle comprising multiple shorter strips or a focused square. In total, 3025 entries are mapped. Red areas constitute a higher concentration of images than -in decreasing order - orange, yellow, green and dark green areas.

1 e.g. Hawk 2003; Albright, Kelleher-Vergantini, and Kim 2014; Bermudez 2017.

2 For this data, these additional criteria apply: Off nadir angle: $0-25^{\circ}$; cloud cover: 0-20\%; bands: pan, pan-MS1; pan-MS1-MS2; minimum sun elevation angle: $0^{\circ}$; spacecrafts: WV-1, WV-2, WV-3, QB-02, GE-1.

*philipp.olbrich@rug.nl 


\section{Private-Public Security Assemblage: Concentrations of U.S. Security Interests}

A visual analysis of the heatmap shows that satellite imagery is not captured in an even pattern but there are areas of higher and lower concentration. Due to the material affordances of high-resolution satellites, they do not capture images of the whole country when over North Korea but only a predetermined selection they are programmed to collect. This procedure is called tasking. As legal owner of the satellites, DigitalGlobe controls tasking operations. And as a private company, customer demandarguably drives large parts of its decisions and, effectively, what parts of North Korea are being imaged. The U.S. government plays an important role in those decisions notonly because the company is based in the United States. According to DigitalGlobe's annual financial reports, the U.S. government regularly accounts for more than 60 percent of its revenue. Above all, the National Geospatial-Intelligence Agency (NGA), which supports the national security mission of the Department of Defense and the U.S. intelligence community, has been DigitalGlobe's single largest customer and takes up a substantial share of the overall image tasking capacity. While past studies have already discussed the intricate relations of the remote sensing industry with the U.S. government, ${ }^{3}$ the heatmap offers an instructive visualization of the security assemblage that blurs the private-public distinction. ${ }^{4}$ Taken together, the material constraints of high-resolution imaging satellites and the NGA's agreement with DigitalGlobe help to understand the heatmap as co-produced by U.S. national security interests.

A large part of the concentrations correspond with well-known locations involved in North Korea's nuclear and missile program and reflect U.S. security interests: This includes the Nyŏngbyŏn nuclear complex (also Yongbyon) and the P'unggye-ri nuclear test site ${ }^{5}$ as well as the Tonghae satellite launching ground (also Musudan-ri) on the East coast and the Sohae satellite launching station on the West coast. ${ }^{6}$ Overall, security-relevant locations feature prominently in the heatmap. To be sure, there are high-resolution satellite images of the whole DPRK. However, the heatmap challenges the idea of a uniform satellitebased transparency that is neutral and free from geopolitical interests. Instead, it reveals that specific areas receive considerably more attention resulting in an uneven, selective and politicized transparency. And since all collections are transferred into an archive, other users draw on a pool of imagery that from the beginning is biased towards U.S. government interests.

3 e.g. Parks 2012; Witjes and Olbrich 2017.

4 Abrahamsen and Williams 2011.

5 e.g. Pabian, Bermudez, and Liu 2018; Puccioni and Serbin 2018.

6 Bermudez, Pabian, and Liu 2018; Hansen 2013. 


\section{Outlook}

Oftentimes, non-governmental actors, policymakers and academics alike take commercial satellite imagery as a neutral instrument of security governance. However, the heatmap points to the socio-material limits and, ultimately, politicized nature of satellite-based transparency. In terms of limitations, the data only covers Digital Globe imagery and none of its (few) competitors outside of the U.S. Moreover, the heatmap is a retrospective look at commercial high-resolution imagery of the past. Recently, a number of commercial remote sensing initiatives have sprung up in the United States which have launched or plan to launch additional imaging satellites. However, most of them do not offer highresolution imagery. Yet, increasing the number of satellites will address some of the concerns regarding data availability over hitherto neglected areas. Overall, the heatmap is no argument against non-governmental remote sensing of the DPRK - to the contrary. However, it does visualize U.S. national security interests and blind spots in commercial imagery coverage, and how they participate in reproducing a largely U.S. representation of North Korea.

\section{Acknowledgements}

I would like to thank Leon van der Meulen and the Geodienst at the University of Groningen for their support in preparing the heatmap. 


\section{References}

Abrahamsen, Rita, and Michael C. Williams. 2011. Security Beyond the State: Private Security in International Politics. Cambridge: Cambridge University Press.

Albright, David, Serena Kelleher-Vergantini, and Priscilla Kim. 2014. "On-Going Activityat North Korea's Punggye-Ri Test Site." Institute for Science and International Security. http://isis-online.org/isis-reports/detail/on-going-activity-at-northkoreaspunggye-ri-test-site/

Bermudez, Joseph S. 2017. "North Korea’s Submarine Ballistic Missile Program Moves Ahead: Indications of Shipbuilding and Missile Ejection Testing." 38 North. https://www.38north.org/2017/11/sinpo111617/

Bermudez, Joseph S., Frank Pabian, and Jack Liu. 2018. "North Korea Likely Preparingfor New Rocket Engine Test at Sohae." 38 North. https://www.38north. org/2018/01/sohae010418/

Hansen, Nick. 2013. "North Korea Halts Construction of New Long-Range Rocket Launch Facilities.” 38 North. https://www.38north.org/2013/07/tonghae072213/

Hawk, David. 2003. “The Hidden Gulag - Exposing North Korea's Prison Camps.” Committee for Human Rights in North Korea. http://www.hrnk.org/uploads/pdfs/ The_Hidden_Gulag.pdf.

Pabian, Frank, Joseph S. Bermudez, and Jack Liu. 2018. "North Korea Has Begun Dismantlement of the Punggye-Ri Nuclear Test Site." 38 North. https://www.38north. org/2018/05/punggye051418/

Parks, Lisa. 2012. "Zeroing in: Overhead Imagery, Infrastructure Ruins, and Datalands in Afghanistan and Iraq." In Communication Matters: Materialist Approaches to Media, Mobility and Networks, edited by Jeremy Packer and Stephen B. Crofts Wiley, 78-92. Abingdon: Routledge.

Puccioni, Allison, and Elliot Serbin. 2018. "North Korean ELWR Makes Progress towards Operations." Jane's. http://www.janes.com/images/assets/853/76853/North_ Korean_ELWR_makes_progress_towards_operations.pdf

Witjes, Nina, and Philipp Olbrich. 2017. "A Fragile Transparency: Satellite Imagery Analysis, Non-State Actors and the Making of International Security Issues." Science and Public Policy 44(4): 524-234. 
North Korea Through the Eyes of the United States: A Heatmap of Commercial Satellite Imagery of North Korea from 2002-2017

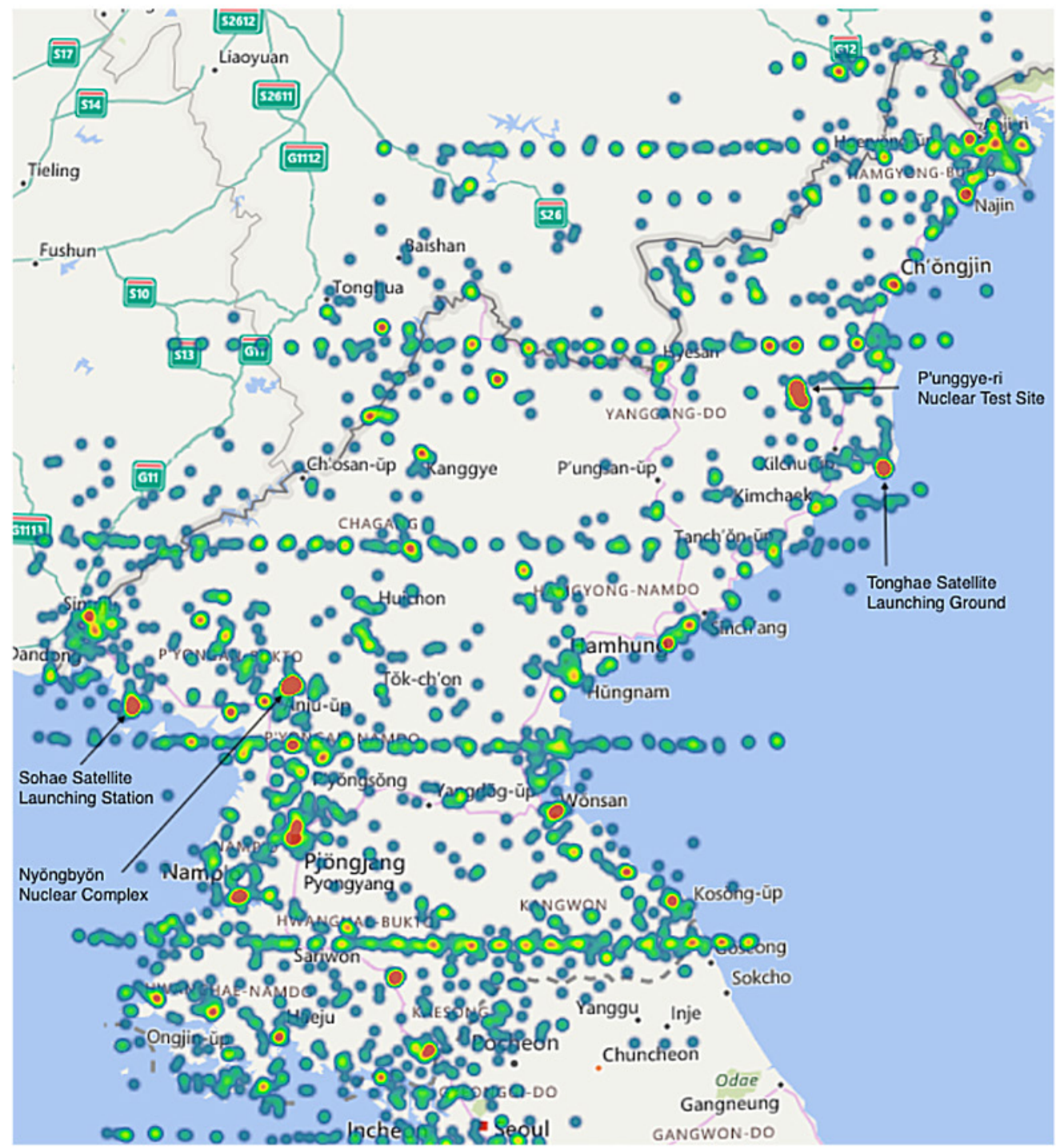

Compiled from DigitalGlobe's ImageFinder data (January 2018) 